\title{
Bioavailability of astaxanthin stereoisomers from wild (Oncorhynchus spp.) and aquacultured (Salmo salar) salmon in healthy men: a randomised, double-blind study
}

\author{
Corinna E. Rüfer*, Jutta Moeseneder, Karlis Briviba, Gerhard Rechkemmer and Achim Bub \\ Institute of Nutritional Physiology, Federal Research Centre for Nutrition and Food, Haid-und-Neu-Strasse 9, \\ 76131 Karlsruhe, Germany
}

(Received 17 July 2007 - Revised 7 September 2007 - Accepted 11 September 2007 - First published online 13 November 2007)

The objective of the present study was to investigate the bioavailability and the configurational isomer distribution of the carotenoid astaxanthin (AST) in human plasma after ingestion of wild (Oncorhynchus spp.) and aquacultured (Salmo salar) salmon. In a randomised and double-blind trial, twenty-eight healthy men consumed $250 \mathrm{~g}$ wild or aquacultured salmon daily for 4 weeks which provided $5 \mu \mathrm{g}$ AST/g salmon flesh. The plasma AST concentrations as well as the isomer distribution were measured by HPLC using a reversed and a chiral stationary phase. After $6 \mathrm{~d}$ of intervention with salmon, plasma AST concentrations reached a plateau of $39 \mathrm{nmol} / 1$ after consumption of wild salmon and of $52 \mathrm{nmol} / 1$ after administration of aquacultured salmon. At days 3, 6, 10 and 14 - but not at day 28 - the AST concentrations in human plasma were significantly greater after ingestion of aquacultured salmon. After administration of wild salmon, the $\left(3 S, 3^{\prime} S\right)$ isomer predominated in plasma $(80 \%)$, whereas after intake of aquacultured salmon the meso form $\left(3 R, 3^{\prime} S\right)$ prevailed $(48 \%)$. Therefore, the AST isomer pattern in human plasma resembles that of the ingested salmon. However, after consumption of both wild and aquacultured salmon for $28 \mathrm{~d}$ the relative proportion of the $\left(3 S, 3^{\prime} S\right)$ isomer was slightly higher and the $\left(3 R, 3^{\prime} R\right)$ form lower in human plasma compared with the isomer distribution in salmon flesh. A selective process of isomer absorption could be responsible for the observed differences in the relative proportions of the $\left(3 S, 3^{\prime} S\right)$ and $\left(3 R, 3^{\prime} R\right)$ isomers in human plasma compared with salmon flesh.

Astaxanthin: Stereoisomers: Bioavailability

The characteristic red to pink-red colour of salmon flesh is due to the presence of carotenoids. Carotenoids are a group of natural fat-soluble pigments that are produced in bacteria, algae, yeasts, moulds and higher plants. Fish like other animals are unable to synthesise carotenoids endogenously. However, they can absorb them from their diets and deposit them in their body. Astaxanthin (AST; 3,3'-dihydroxy- $\beta, \beta$-carotene4,4'-dione) (Fig. 1) is the main carotenoid found in the flesh of wild Atlantic salmon (Salmo salar) and Pacific salmon

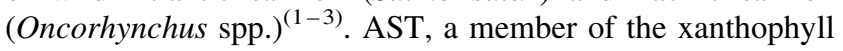
group, exhibits strong antioxidant properties and does not have any vitamin A activity ${ }^{(4)}$. Wild salmon acquire their pink-red colour from the AST of their prey. The main sources are zooplankton (including calanoid copepods and krill), other crustaceans and red fish oils (including capelin oil). To obtain a flesh colour similar to that of wild salmon, aquacultured salmon are fed fish feed fortified with AST amongst others things. Today AST is the preferred pigment added to salmon feed. It is present in nature, but it can also be produced by chemical synthesis (for example, Carophyll Pink ${ }^{\circledR}$ ). These synthetic forms are commonly used in conventional fish farms ${ }^{(2,5)}$. According to the Council Directive 70/524/EEC on additives in feedstuffs the use of AST is permitted up to a maximum level of $100 \mathrm{mg} / \mathrm{kg}$ from the age of 6 months onwards.
All-trans-AST is the major geometric isomer in wild salmon flesh and also in the stabilised synthetic AST beadlet added to the fish feed of aquacultured salmon. All-transAST has two asymmetric carbons at the $\mathrm{C}-3$ and $\mathrm{C}-3^{\prime}$ positions and can exist as three stereoisomers: two enantiomers $\left(\left(3 R, 3^{\prime} R\right)\right.$ and $\left.\left(3 S, 3^{\prime} S\right)\right)$ and a meso form $\left(\left(3 R, 3^{\prime} S\right)\right.$ and $\left(3 S, 3^{\prime} R\right)$, respectively)) (Fig. 1$)^{(6)}$. Synthetic all-trans-AST consists of the two enantiomers $\left(\left(3 R, 3^{\prime} R\right)\right.$ and $\left.\left(3 S, 3^{\prime} S\right)\right)$ and the meso form in the ratio $1: 1: 2$, respectively. The yeast Xanthophyllomyces dendrorhous is able to biosynthesise AST as its principal pigment with the configuration $\left(3 R, 3^{\prime} R\right)$. A study by the US Food and Drug Administration showed that the $\left(3 S, 3^{\prime} S\right)$ isomer is the main form found in wild Pacific and Atlantic salmon species. Furthermore, small portions of the meso form and the $\left(3 R, 3^{\prime} R\right)$ isomer are detectable ${ }^{(5,7,8)}$. Feeding studies with Atlantic salmon have shown that the configurational isomers are deposited in the flesh of the salmon with no change in the distribution when synthetic AST or the individual stereoisomers are added to fish feed ${ }^{(9)}$. These results indicate the absence of selective absorption or deposition mechanisms of the different stereoisomers as well as of isomerisation at $\mathrm{C}-3$ and $\mathrm{C}-3^{\prime}$. Therefore, the ratio of configurational isomers in salmon flesh reflects the stereoisomer distribution in the diet. 
(A)<smiles>CC(/C=C/C=C/C=C(C)/C=C/C1=CC(=O)[C@@H](O)CC1(C)C)=C\C=C\C=C(C)\C=C\C=C(C)\C=C\C1=CC(=O)[C@@H](O)CC1(C)C</smiles>

(B)<smiles>CC(/C=C/C=C/C=C/C=C(C)/C=C/C1=CC(=O)C(O)CC1(C)C)=C\C=C\C=C(C)\C=C\C=C(C)\C=C\C1=CC(=O)C(O)CC1(C)C</smiles>

(C)

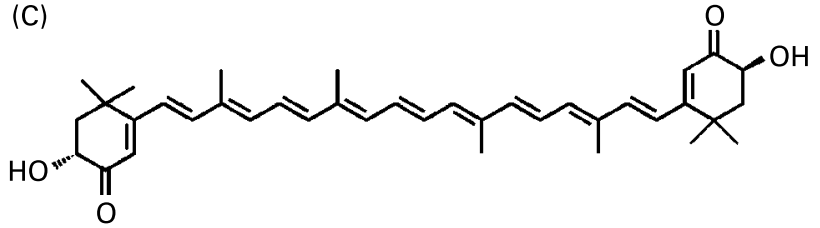

Fig. 1. Configurational isomers of all-trans-astaxanthin (AST): $\left(3 R, 3^{\prime} R\right)$ all-transAST (A); (3S,3'S) all-trans-AST (B); (3R,3'S) all-trans-AST (meso form) (C).

So far, little is known about the bioavailability of AST from different food sources in humans. The same holds true for the configurational isomer distribution. Questions have arisen as to whether the configurational isomer distribution reflects the distribution in the diet or whether selective absorption, deposition or isomerisation mechanisms apply. Therefore, the objective of the present study was to investigate the bioavailability and the configurational isomer distribution in the human plasma of twenty-eight men, after ingestion of $250 \mathrm{~g}$ wild or aquacultured salmon daily for 4 weeks. The chromatographic resolution of the stereoisomers was achieved by HPLC using a chiral stationary phase.

\section{Materials and methods}

\section{Fish samples}

Fresh gutted and deskinned wild salmon (Oncorhynchus spp.) was purchased in $250 \mathrm{~g}$ samples as deep-frozen fish from Iceland (Icelandic Freezing Plants Handels GmbH, Hamburg, Germany). Aquacultured salmon (S. salar) was obtained as fresh gutted and deskinned fish from Norway (Deutsche See, Bremerhaven, Germany). Samples of $250 \mathrm{~g}$ were prepared, sealed under vacuum and frozen at $-30^{\circ} \mathrm{C}$. Samples of wild and aquacultured salmon were stored at $-30^{\circ} \mathrm{C}$ until analysis in our laboratory and distribution to the study participants. According to our analysis, both wild salmon and aquacultured salmon provided $5 \mu \mathrm{g} \mathrm{AST/g}$ fresh weight (see Results).

\section{Chemicals}

Synthetic AST was purchased from Sigma-Aldrich (Taufkirchen, Germany). The yeast $X$. dendrorhous was kindly donated by U. Ostermeyer (Federal Research Centre for Nutrition and Food, Hamburg, Germany). The carotenoids of the yeast were extracted in the same way as those in the salmon (see below). All other chemicals were purchased from Carl
Roth (Karlsruhe, Germany) or from Sigma-Aldrich (Taufkirchen, Germany).

\section{Subjects}

Twenty-eight healthy men aged 20-49 years were recruited for the study through advertisements posted at local universities, at other institutions and in regional newspapers. Exclusion criteria were smoking and use of dietary supplements or medication. All subjects were in good medical health, as was determined by a screening history and a medical examination. In Table 1 the blood lipid parameters of the volunteers before and after the intervention are summarised. BMI ranged between 19.8 and $29.2 \mathrm{~kg} / \mathrm{m}^{2}$ (mean 23.7 (SD 2.0) $\mathrm{kg} / \mathrm{m}^{2}$ ). Body fat was calculated by bioelectrical impedance analysis and was determined to be 8.3 to $25.1 \%$ (mean 16.5 (SD 4.8 ) \%). The study was approved by the Medical Ethical Committee of the Landesärztekammer Baden-Württemberg, and all participants gave their written consent.

\section{Study design}

The study was based on a randomised and double-blind trial of a 4-week treatment. Study participants were allocated to two groups ( $n 14$ per group). Intervention was preceded by a 2-week low-AST period where subjects were asked to refrain from foods containing AST (for example, salmon, crabs, lobster, seafood). A list of AST-containing foods was provided. During the intervention, subjects were told to consume $250 \mathrm{~g}$ wild or aquacultured salmon as a whole portion daily with their main meals (lunch or dinner). The choice of preparation of the salmon was left to the participants in order to have a realistic every-day situation and a better compliance over 4 weeks. However, a booklet was handed out to the volunteers with eight recipes which they should exclusively use for preparation. The subjects were not restricted in their daily diet, except that they had to abstain from food high in AST throughout the whole study period.

\section{Collection and preparation of blood samples}

Fasting blood samples were taken in the morning between 07.00 and 09.00 hours at baseline as well as on days 3,6 , 10,14 and 28 of the intervention. Blood was drawn from an antecubital vein into prechilled tubes containing EDTA

Table 1. Blood lipid parameters of the participants before and after $28 d$ of intervention with wild and aquacultured salmon, respectively (Mean values and standard deviations)

\begin{tabular}{lcccrr}
\hline & \multicolumn{3}{c}{ Blood lipid parameters (mg/l) } \\
\cline { 2 - 3 } & \multicolumn{2}{c}{ Day 0 } & & \multicolumn{2}{c}{ Day 28 } \\
\cline { 2 - 3 } \cline { 5 - 6 } & Mean & SD & & Mean & SD \\
\hline TAG & $1095^{\star}$ & 393 & 874 & 311 \\
Cholesterol & 1776 & 342 & 1811 & 299 \\
HDL-cholesterol & 537 & 63 & 541 & 49 \\
LDL-cholesterol & 1232 & 269 & 1269 & 213
\end{tabular}

\footnotetext{
* Mean value is significantly different from that at day $28(P<0.05$; unpaired
} Student's $t$ test). 
(1.6 g/l; Monovette-Sarstedt, Nümbrecht, Germany) and immediately placed on ice in the dark. Plasma was collected after centrifugation at $1500 \mathrm{~g}$ for $10 \mathrm{~min}$ at $4^{\circ} \mathrm{C}$. Tubes without anticoagulant (Serum-Monovette-Sarstedt, Nümbrecht, Germany) were used for serum collections. Blood was allowed to clot at room temperature for $30 \mathrm{~min}$, then centrifuged at $1500 \mathrm{~g}$ for $10 \mathrm{~min}$ at room temperature, and serum stored at $-80^{\circ} \mathrm{C}$ until analysis.

\section{Analytical methods}

Lipid extraction from salmon. Total lipid content in salmon was determined according to the method described by Folch et al. ${ }^{(10)}$. Salmon $(500 \mathrm{~g})$ was homogenised using a laboratory blender (B400; Büchi Labortechnik GmbH, Essen, Germany); $1 \mathrm{~g}$ was further homogenised in $20 \mathrm{ml}$ chloroform-methanol $(2: 1, \mathrm{v} / \mathrm{v})$ containing $1 \%$ 3,5-di-tert-4-butylhydroxytoluene (BHT) using an Ultra Turrax T25 (IKA Labortechnik, Jahnke und Kunkel, Staufen, Germany). After filtration through a filter paper (no. 595; Schleicher \& Schuell, Dassel, Germany) the crude extract was mixed with $4 \mathrm{ml}$ water containing $0.02 \% \mathrm{CaCl}_{2}$ and the mixture was separated into two phases by centrifugation for $5 \mathrm{~min}$ at $3000 \mathrm{~g}$. The upper phase was removed using a Pasteur pipette and the lower phase was rinsed three times with $1 \mathrm{ml}$ chloroformmethanol-water (3:48:47, by vol.). The weight of total lipid was determined gravimetrically after evaporation of the solvent and overnight desiccation in vacuo.

Astaxanthin extraction from salmon. Samples of $2 \mathrm{~g}$ homogenised salmon flesh (see above) was further homogenised in $50 \mu \mathrm{l} 100 \mathrm{~mm}$-EDTA and $5 \mathrm{ml}$ acetone containing 0.01\% BHT using an Ultra Turrax T25. The homogenate was centrifuged at $3000 \mathrm{~g}$ for $5 \mathrm{~min}$ at $4^{\circ} \mathrm{C}$ and the organic extracts were collected in a separate tube. Extraction was repeated until the organic extracts were colourless. After washing the combined organic extracts with $5 \mathrm{ml}$ of a saturated $\mathrm{NaCl}$ solution the organic solvent was removed using a rotary evaporator (Laborota 4003-digital; Heidolph, Schwabach, Germany). The remaining aqueous phase was extracted three times with $2 \mathrm{ml} n$-hexane containing $0.01 \%$ BHT and the combined organic extracts were evaporated to dryness under a stream of $\mathrm{N}_{2}$ gas.

Astaxanthin extraction from plasma. AST was extracted from $1 \mathrm{ml}$ plasma as described by Briviba et al. ${ }^{(11)}$. Briefly, after protein precipitation with ice-cold ethanol, AST was extracted three times with $2 \mathrm{ml} n$-hexane-dichloromethane $(5: 1(\mathrm{v} / \mathrm{v})$, with $0.01 \%$ of BHT) in an ultrasonic bath for $5 \mathrm{~min}$. The combined organic extracts were evaporated to dryness under a stream of $\mathrm{N}_{2}$.

Reversed-phase and chiral high-performance liquid chromatography analysis. HPLC analysis was performed on a low-pressure gradient system from Shimadzu (Duisburg, Germany) equipped with an auto-injector, column oven and photodiode array detector. The auto-injector was set to $10^{\circ} \mathrm{C}$ and the column oven to $27^{\circ} \mathrm{C}$.

For the quantitative determination of the AST concentration in fish and plasma samples with reversed-phase chromatography the residues were redissolved in either $5 \mathrm{ml}$ or $200 \mu \mathrm{l}$ acetone-dichloromethane $(10: 1(\mathrm{v} / \mathrm{v})$, with $0.01 \%$ of BHT). For HPLC analysis, $50 \mu \mathrm{l}$ was used. Separation was carried out on a $250 \times 4.6 \mathrm{~mm}$ internal diameter, $5 \mu \mathrm{m}$,
YMC 'Carotenoid' S5 reversed-phase C30 column with the corresponding $10 \times 4.6 \mathrm{~mm}$ internal diameter guard column (YMC Europe GmbH, Dinslaken, Germany). Solvent A consisted of tert-butyl methyl ether, solvent B of methanol and solvent $\mathrm{C}$ of water. A linear gradient was used starting with $81 \% \mathrm{~B}$ and $4 \% \mathrm{C}$ going to $21.1 \% \mathrm{~B}$ and $4 \% \mathrm{C}$ within $70 \mathrm{~min}$. The flow rate was $1 \mathrm{ml} / \mathrm{min}$ and the detection wavelength was set to $\lambda=470 \mathrm{~nm}$. Quantification was performed by external calibration with synthetic AST. The concentration of a stock solution of the standard in $n$-hexane was measured spectrophotometrically $(\varepsilon=125100 \text { litres } /(\mathrm{mol} \times \mathrm{cm}) \text { at } \lambda=470 \mathrm{~nm})^{(12)}$. A calibration curve of AST was constructed in the range $0 \cdot 1-50 \mu \mathrm{mol} / \mathrm{l}$, in which the linearity of the response was given. The limit of detection was $500 \mathrm{fmol}$. The recovery was greater than $95 \%$. The intra- and inter-assay coefficients were always less than $5 \%$.

For the separation of the AST isomers in fish and plasma samples with chiral chromatography the residues were dissolved in $2 \mathrm{ml} n$-hexane-acetone $(9: 1(\mathrm{v} / \mathrm{v})$, with $0.01 \%$ of BHT) and $70 \mu \mathrm{l} n$-hexane-acetone $(6: 1(\mathrm{v} / \mathrm{v})$, with $0.01 \%$ of BHT), respectively. Samples of $50 \mu$ l were injected onto a $250 \times 4.6 \mathrm{~mm}$ internal diameter, $5 \mu \mathrm{m}$, Sumichiral OA2000 column (Varian, Darmstadt, Germany). The column was eluted isocratically with $n$-heptane-dichloromethane-2propanol (70:25:5, by vol.) at a flow rate of $1 \mathrm{ml} / \mathrm{min}$. The detection was performed at a wavelength of $\lambda=470 \mathrm{~nm}$. The peaks were identified by comparison of the retention times with those of the synthetic AST standard and the AST isolated from the yeast $X$. dendrorhous.

\section{Statistical analysis}

All statistical calculations were performed using StatView (1998; SAS Institute, Cary, NC, USA). Results are reported as mean values and standard deviations. Differences between the mean values of the AST concentrations and total lipid contents in salmon, as well as between the configurational isomer distribution in plasma compared with salmon, were statistically analysed using the unpaired Student's $t$ test. Changes between the baseline $(0 \mathrm{~d})$ and the following time points among the two treatment groups were tested for significance by repeated-measures ANOVA and the Tukey-Kramer post hoc test. Differences were considered significant at $P<0 \cdot 05$.

\section{Results}

Separation of the configurational AST isomers was performed on a Sumichiral OA-2000 column (Varian, Darmstadt, Germany), which is prepared by covalently bonding 3,5-dinitrobenzoyl-D-phenylglycine to silica. The peaks were identified by comparing the retention times with those of the synthetic AST standard and the AST isolated from the yeast $X$. dendrorhous. The percentages of the all-trans stereoisomers in the standard solutions of synthetic AST and of AST extracted from $X$. dendrorhous are summarised in Table 2. Synthetic AST contained the $\left(3 R, 3^{\prime} R\right),\left(3 R, 3^{\prime} S\right)$ and $\left(3 S, 3^{\prime} S\right)$ forms in the ratio of about $1: 2: 1$, whereas the $\left(3 R, 3^{\prime} R\right)$ isomer was the only form present in $X$. dendrorhous. In Fig. 2 the corresponding chiral HPLC chromatograms are depicted. 
Table 2. Configurational isomer distribution of synthetic all-trans-astaxanthin (AST) and AST extracted from Xanthophyllomyces dendrorhous

(Mean values and standard deviations for three determinations)

\begin{tabular}{|c|c|c|c|c|c|c|}
\hline & \multicolumn{6}{|c|}{ AST isomer distribution (\%) } \\
\hline & \multicolumn{2}{|c|}{$3 R, 3^{\prime} R$} & \multicolumn{2}{|c|}{$3 R, 3^{\prime} S$} & \multicolumn{2}{|c|}{$3 S, 3^{\prime} S$} \\
\hline & Mean & SD & Mean & SD & Mean & SD \\
\hline Synthetic AST & $20 \cdot 8$ & 0.7 & $51 \cdot 2$ & 1.0 & $28 \cdot 0$ & 1.5 \\
\hline Xanthophyllomyces dendrorhous & $100 \cdot 0$ & 0.0 & 0.0 & 0.0 & $0 \cdot 0$ & 0.0 \\
\hline
\end{tabular}

AST and total lipid content as well as the configurational isomer distribution of all-trans-AST in the muscle tissue of wild and aquacultured salmon are shown in Table 3. Both types of salmon contained $5 \mu \mathrm{g}$ AST/g salmon flesh. The muscle tissue of wild salmon was comprised predominantly of the $\left(3 S, 3^{\prime} S\right)$ isomer (about $\left.70 \%\right)$, whereas in aquacultured salmon the meso form $\left(3 R, 3^{\prime} S\right)$ was the major isomer (about $48 \%)$ and both enantiomers $\left(\left(3 R, 3^{\prime} R\right)\right.$ and $\left.\left(3 S, 3^{\prime} S\right)\right)$ were present in comparable amounts. In Fig. 3 the corresponding chiral HPLC chromatograms of wild and aquacultured salmon are shown. The average total lipid content of aquacultured salmon was about three times greater than that of wild salmon (Table 3).

The mean plasma AST concentrations and the configurational isomer distribution are listed in Table 4. Oral administration of AST from wild and aquacultured salmon led to the absorption of AST into plasma without any appreciable metabolic transformation. AST was not detected in plasma on day 0 , collected before intake of the salmon meals. However, other carotenoids ( $\alpha$ - and $\beta$-carotene, lycopene, lutein, zeaxanthin, $\beta$-cryptoxanthin) were present in the plasma taken at all time points (data not shown). After $6 \mathrm{~d}$ of intervention with salmon, AST concentrations reached a plateau of about $39 \mathrm{nmol} / \mathrm{l}$ after consumption of wild salmon and of about

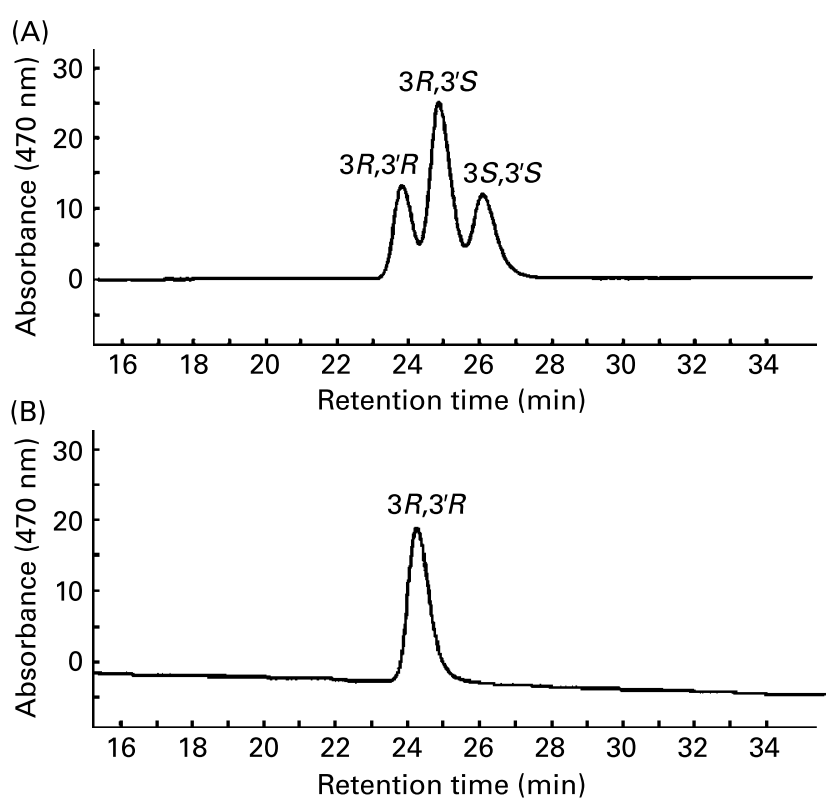

Fig. 2. Representative chiral HPLC chromatograms of (A) synthetic astaxanthin (AST) and (B) AST extracted from Xanthophyllomyces dendrorhous.
$52 \mathrm{nmol} / \mathrm{l}$ after administration of aquacultured salmon. On days 3, 6, 10 and 14 the AST concentrations in human plasma were always significantly greater after intake of aquacultured salmon. After consumption of wild salmon the $\left(3 S, 3^{\prime} S\right)$ isomer predominated in plasma (about $\left.80 \%\right)$ whereas after intake of aquacultured salmon the meso form $\left(3 R, 3^{\prime} S\right)$ prevailed (about $48 \%$ ). Therefore, the AST isomer pattern in human plasma resembles that of the ingested salmon flesh. However, chiral chromatography revealed differences in the presence of specific configurational isomers of alltrans-AST in human plasma over $28 \mathrm{~d}$ compared with muscle tissue of wild and aquacultured salmons, respectively (Fig. 4). The relative proportion of the $\left(3 R, 3^{\prime} R\right)$ isomer was significantly lower in human plasma after consumption of wild and aquacultured salmon over $28 \mathrm{~d}$. The $\left(3 S, 3^{\prime} S\right)$ isomer was significantly higher after consumption of wild salmon. There was a similar trend for the $\left(3 S, 3^{\prime} S\right)$ isomer after intake of aquacultured salmon $(P<0.08)$. Statistical comparison of the configurational isomer distribution in human plasma on days $3,6,10,14$ and 28 with that of wild and aquacultured salmon revealed that the relative proportion of the $\left(3 R, 3^{\prime} R\right)$ isomer was significantly lower and the $\left(3 S, 3^{\prime} S\right)$ isomer higher in human plasma at all time points except for day 28 (data not shown)

\section{Discussion}

Feeding studies with Atlantic salmon have shown that the configurational isomers are deposited in the salmon flesh with no change in the stereoisomer distribution. However, to date, it is not known whether the stereoisomer distribution in the diet also reflects the ratio of configurational isomers in human plasma. Therefore, the objective of the present study was to investigate the bioavailability of AST from different food sources and the configurational isomer distribution in human plasma after ingestion of both wild and aquacultured salmon.

In agreement with data from the current literature we were able to demonstrate that salmon are unable to modify the chemical configuration of the AST molecule (Tables 2 and 3$)^{(5-8)}$. Consequently, in salmon selective absorption or deposition mechanisms of the different stereoisomers as well as of isomerisation at C-3 and C- $3^{\prime}$ do not apply. Since the configurational isomer distribution of AST in wild salmon flesh varies due to differences in origin (AST from prey and synthetic AST added to fish feed) the isomeric AST patterns help to distinguish between wild and aquacultured salmon, and so could help to protect the consumer from being 
Table 3. Astaxanthin (AST) and total lipid contents as well as the configurational isomer distribution of all-trans-AST in muscle tissue of wild (Oncorhynchus spp.) and aquacultured (Salmo salar) salmon (Mean values and standard deviations for three determinations)

\begin{tabular}{|c|c|c|c|c|c|c|c|c|c|c|}
\hline & & & & & \multicolumn{6}{|c|}{ AST isomer distribution (\%) } \\
\hline & \multicolumn{2}{|c|}{$\begin{array}{l}\text { Total lipids } \\
\text { ( } / 100 \mathrm{~g} \text { fillet) }\end{array}$} & \multicolumn{2}{|c|}{$\begin{array}{c}\text { AST } \\
(\mu \mathrm{g} / \mathrm{g} \text { fillet })\end{array}$} & \multicolumn{2}{|c|}{$3 R, 3^{\prime} R$} & \multicolumn{2}{|c|}{$3 R, 3^{\prime} S$} & \multicolumn{2}{|c|}{$3 S, 3^{\prime} S$} \\
\hline & Mean & SD & Mean & SD & Mean & SD & Mean & SD & Mean & SD \\
\hline Wild salmon & $6 \cdot 54^{*}$ & 0.07 & 5.03 & 0.05 & $28 \cdot 2$ & 0.8 & $2 \cdot 1$ & 0.2 & $39 \cdot 7$ & $1 \cdot 0$ \\
\hline Aquacultured salmon & $17 \cdot 28$ & 0.15 & 4.95 & 0.11 & $20 \cdot 3$ & 0.1 & $47 \cdot 8$ & 0.3 & 31.9 & 0.4 \\
\hline
\end{tabular}

${ }^{*}$ Mean value is significantly different from that of the aquacultured salmon $(P<0.001$; unpaired Student's $t$ test $)$.

misled. Further details are discussed by Turujman et al. and Ostermeyer \& Schmidt ${ }^{(7,8)}$.

Oral administration of AST from wild and aquacultured salmon leads to the absorption of AST into plasma without any appreciable metabolic transformation. On days 3, 6, 10 and 14 the AST concentrations in human plasma were significantly greater after consumption of aquacultured salmon (Table 4). The question arises of why plasma AST concentrations are lower after intake of wild salmon despite comparable AST concentrations in the flesh of the two types of salmon. Absorption of carotenoids is facilitated by dietary fat concentration. Higher amounts of fat means a better solubility of carotenoids and this may imply easier incorporation in gastrointestinal mixed micelles ${ }^{(13,14)}$. Since aquacultured salmon contains three times more total lipids than wild salmon (Table 3 ) the fat content of the salmon may be responsible for the differences in AST bioavailability. However, lipid increases in excess of about $10 \mathrm{~g} / \mathrm{meal}$ do not increase carotenoid absorption $^{(13,14)}$. Fat $(16 \cdot 5 \mathrm{~g})$ after a meal with $250 \mathrm{~g}$ wild salmon or $43.25 \mathrm{~g}$ fat after intake of $250 \mathrm{~g}$ aquacultured salmon plus further dietary fat ingested along with the salmon is far greater than the cut-off of about $10 \mathrm{~g}$.

\section{(A)}
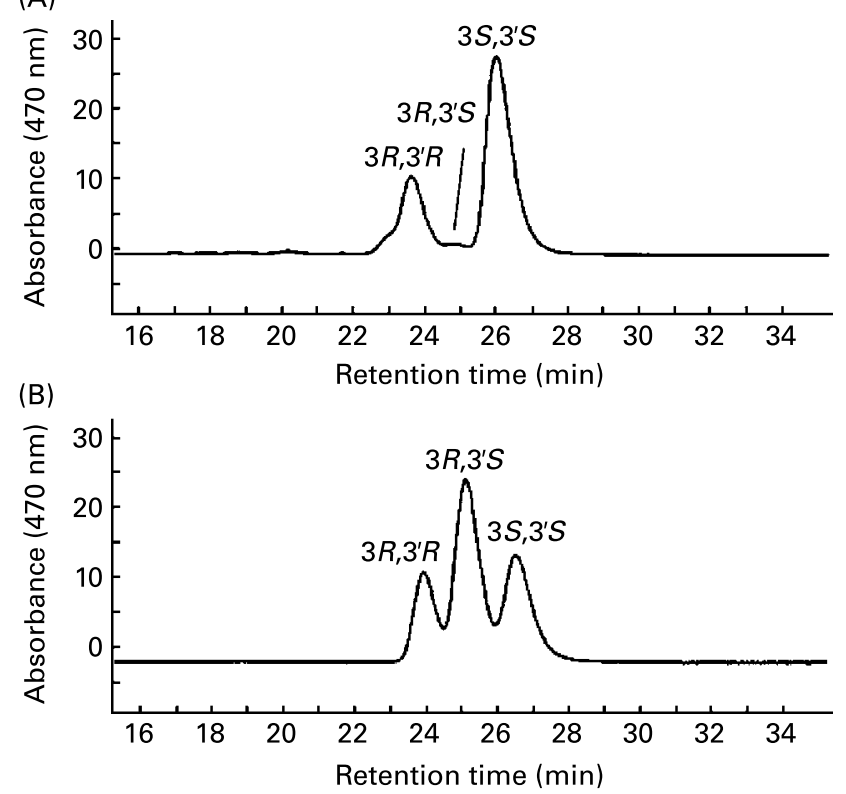

Fig. 3. Representative chiral HPLC chromatograms of $(A)$ wild (Oncorhynchus spp.) and (B) aquacultured (Salmo salar) salmon.
One might speculate that the fatty acid composition is important. In particular, differences in the concentrations of EPA and DHA which are almost exclusively derived from fish may play a role. It is noteworthy that after $28 \mathrm{~d}$ of oral intake of wild and aquacultured salmon, respectively, no significant differences between the plasma AST concentrations are observable (Table 4). Possibly, differences in bioavailability may be only observed in short-term experiments and increasing the duration of the study may lead to a steady state of absorption, metabolism, distribution and/or elimination.

By comparing peak plasma AST concentrations reported in the literature with the concentrations of the present study it is noteworthy that a non-linear response for AST concentrations in human plasma after administration of different doses is observable. Elmadfa \& Majchrzak administered a single dose of $500 \mathrm{~g}$ salmon corresponding to $1.5 \mathrm{mg}$ AST to five human subjects. They were unable to detect AST in human

Table 4. Plasma astaxanthin (AST) concentrations and distribution of the configurational isomers of all-trans-AST at baseline and over the intervention period with wild (Oncorhynchus spp.) and aquacultured (Salmo salar) salmon for $28 \mathrm{~d}$

(Mean values and standard deviations for fourteen male subjects per group)

\begin{tabular}{|c|c|c|c|c|c|c|c|c|}
\hline & & & \multicolumn{6}{|c|}{ AST isomer distribution (\%) } \\
\hline & \multicolumn{2}{|c|}{$\begin{array}{c}\text { Plasma } \\
\text { AST (nmol/l) }\end{array}$} & \multicolumn{2}{|c|}{$3 R, 3^{\prime} R$} & \multicolumn{2}{|c|}{$3 R, 3^{\prime} S$} & \multicolumn{2}{|c|}{$3 S, 3^{\prime} S$} \\
\hline & Mean & SD & Mean & SD & Mean & SD & Mean & SD \\
\hline \multicolumn{9}{|c|}{ Wild salmon group } \\
\hline Day 0 & \multicolumn{2}{|c|}{ ND } & \multicolumn{2}{|c|}{ ND } & \multicolumn{2}{|c|}{ ND } & \multicolumn{2}{|c|}{ ND } \\
\hline Day 3 & $27 \cdot 3^{*}$ & $14 \cdot 9$ & 14.9 & $4 \cdot 2$ & $3.2 \dagger$ & 3.2 & 83.4 & 5.5 \\
\hline Day 6 & $33 \cdot 7^{*}$ & $16 \cdot 2$ & $18 \cdot 5$ & $3 \cdot 7$ & $1.7 \dagger$ & 1.5 & $81 \cdot 5$ & $4 \cdot 1$ \\
\hline Day 10 & $33 \cdot 5^{\star}$ & $11 \cdot 1$ & $18 \cdot 0$ & $2 \cdot 9$ & $2 \cdot 3 \dagger$ & 1.5 & $80 \cdot 1$ & $3 \cdot 7$ \\
\hline Day 14 & $30 \cdot 4^{*}$ & $9 \cdot 6$ & $16 \cdot 8$ & $4 \cdot 0$ & $2 \cdot 1 \dagger$ & 1.5 & $82 \cdot 3$ & 4.4 \\
\hline Day 28 & 38.7 & $20 \cdot 1$ & $16 \cdot 8$ & $5 \cdot 1$ & $6 \cdot 6 \dagger$ & 3.4 & 79.9 & $7 \cdot 6$ \\
\hline \multicolumn{9}{|c|}{ Aquacultured salmon group } \\
\hline Day 0 & \multicolumn{2}{|c|}{ ND } & \multicolumn{2}{|c|}{ ND } & \multicolumn{2}{|c|}{ ND } & \multicolumn{2}{|c|}{ ND } \\
\hline Day 3 & $42 \cdot 0$ & $15 \cdot 0$ & $16 \cdot 7$ & $1 \cdot 2$ & $48 \cdot 0$ & $2 \cdot 1$ & $35 \cdot 3$ & 2.5 \\
\hline Day 6 & $52 \cdot 4$ & $16 \cdot 2$ & $17 \cdot 0$ & 0.9 & $48 \cdot 1$ & 0.8 & 34.9 & $1 \cdot 2$ \\
\hline Day 10 & $47 \cdot 3$ & $16 \cdot 3$ & $17 \cdot 0$ & $2 \cdot 1$ & $46 \cdot 9$ & 1.2 & $36 \cdot 1$ & $2 \cdot 8$ \\
\hline Day 14 & $48 \cdot 1$ & 19.5 & $14 \cdot 8$ & $1 \cdot 7$ & $46 \cdot 8$ & 2.9 & 38.4 & $2 \cdot 6$ \\
\hline Day 28 & $43 \cdot 1$ & 19.5 & $16 \cdot 4$ & 3.0 & $50 \cdot 2$ & 7.0 & 33.4 & 5.6 \\
\hline
\end{tabular}

ND, not detected.

* Mean value is significantly different from that of the aquacultured salmon $(P<0.05$; Tukey-Kramer post hoc test)

†For days $3,6,10,14$ and $28, n 6, n 8, n 11, n 6$ and $n 7$, respectively (since for the other participants the concentration of the $\left(3 R, 3^{\prime} S\right)$ isomer was below the limit of detection). 
(A)

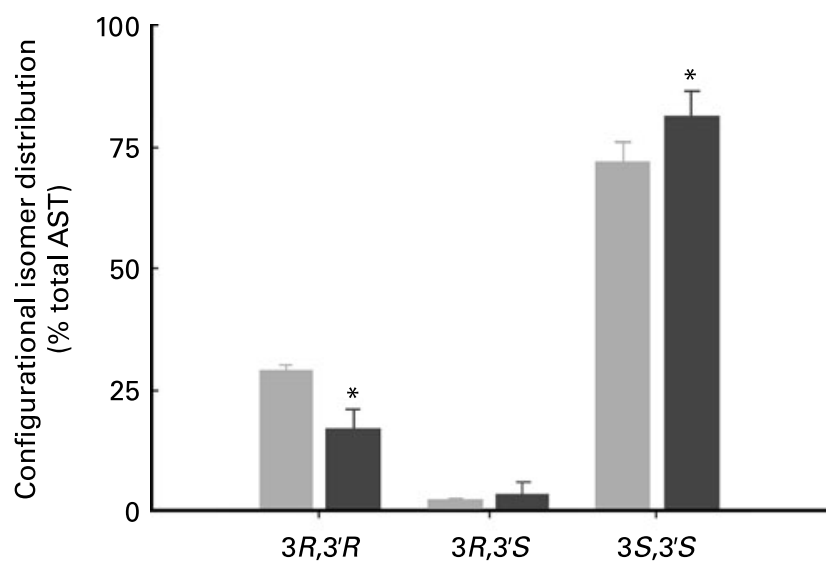

(B)

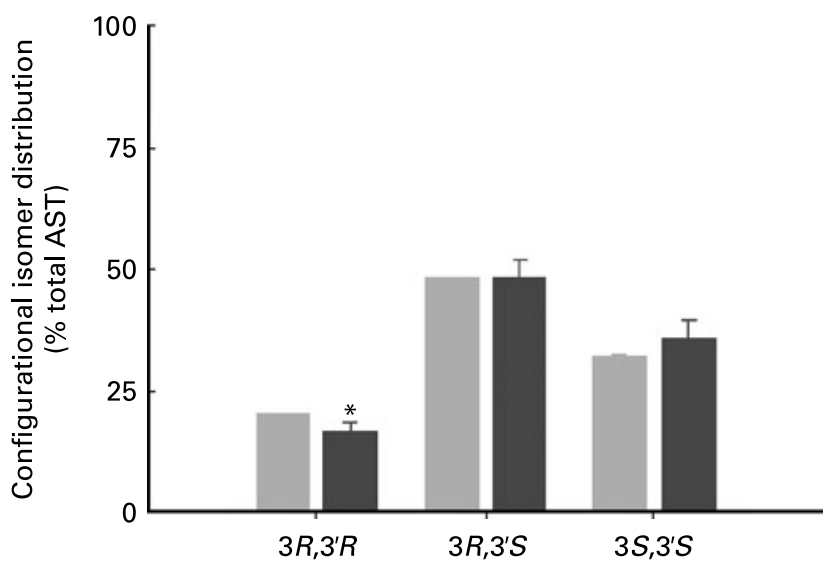

Fig. 4. Configurational isomer distribution of all-trans-astaxanthin (AST) in muscle tissue of wild (Oncorhynchus spp.) (A) and aquacultured (Salmo salar) salmon (B) $(\square)$ and in human plasma $(\square)$ after intake of wild and aquacultured salmon over $28 \mathrm{~d}$. Values are means, with standard deviations represented by vertical bars. * Mean value is significantly different from that in the salmon muscle tissue $(P<0.01$; unpaired Student's $t$ test).

plasma, since concentrations were below the limit of detection $(20 \mathrm{nmol} / \mathrm{l})^{(15)}$. Mercke Odeberg et al. provided a single-bolus dose of $40 \mathrm{mg}$ to thirty-two participants in different lipidbased formulations resulting in peak plasma concentrations between 100 and $350 \mathrm{nmol} / \mathrm{l}^{(16)}$. Osterlie et al. ${ }^{(17)}$, CoralHinostroza et $a{ }^{(18)}$ as well as Kistler et $a l .{ }^{(19)}$ administered a single dose of $100 \mathrm{mg}$ AST to two to three volunteers and recorded maximal plasma AST concentrations of $2.2 \mu \mathrm{mol} / 1$, $500 \mathrm{nmol} / \mathrm{l}$ and $250 \mathrm{nmol} / 1$, respectively ${ }^{(17-19)}$. Furthermore, Coral-Hinostroza et al. detected a maximal plasma concentration of $150 \mathrm{nmol} / 1$ after administration of $10 \mathrm{mg} \mathrm{AST}{ }^{(18)}$. In the present study $1.25 \mathrm{mg}$ AST were provided to twentyeight human subjects resulting in plasma concentrations of $27 \cdot 3$ to $42.0 \mathrm{nmol} / \mathrm{l}$ on day 3 (Table 4 ). These results indicate a non-linear response for plasma AST concentrations in human subjects. This might be due to saturation of enterocyte absorption and transport mechanisms using higher doses.

Small differences in the presence of specific configurational isomers of all-trans-AST in human plasma compared with muscle tissue of wild and aquacultured salmons have been observed in the present study. Comparison of the configurational isomer distribution in human plasma on days $3,6,10,14$ and 28 with that of wild and aquacultured salmon revealed that the relative proportion of the $\left(3 R, 3^{\prime} R\right)$ isomer was significant lower and the $\left(3 S, 3^{\prime} S\right)$ isomer higher in human plasma at all time points except for the plasma sample taken on day 28. The isomer distribution pattern in different biological samples is the combined result of possible isomerisation reactions after ingestion, isomer discrimination during absorption and incorporation in blood particles, and/or discrimination during metabolism. In contrast to the present results Osterlie et al. found the same isomer distribution in human plasma after administration of a single-bolus dose of $100 \mathrm{mg}$ AST to three volunteers and in the administered synthetic $\mathrm{AST}^{(17)}$. However, Bjerkeng and colleagues reported considerable accumulation of the $\left(3 R, 3^{\prime} R\right)$ isomer of about $20 \%$ in human plasma after single-dose administration of AST diesters ${ }^{(18)}$. Similar results have been reported for salmonid fishes after administration of AST diesters. Thus, when AST diesters were supplied to the diets of rainbow and sea trout increased levels of the $\left(3 R, 3^{\prime} R\right)$ isomer were found in the muscle tissue. However, when pure AST is provided, the configurational isomer distribution in muscle tissue of salmonid fishes reflects that of the $\operatorname{diet}^{(9,20,21)}$. The increased levels of the $\left(3 R, 3^{\prime} R\right)$ isomer after administration of AST diesters are thought to be due to the preference of intestinal enzymes hydrolysing predominantly specific isomers of carotenol esters. The present results indicate a small preference for the $\left(3 S, 3^{\prime} S\right)$ isomer in human plasma, contradicting the findings of Osterlie and coworkers who reported that the optical isomer distribution in plasma resembled that of the dose ${ }^{(17)}$. The intake of pharmacological doses, however, may change selectivity due to saturation in absorption or isomerisation. It is noteworthy that in the present study a small preference for the $\left(3 S, 3^{\prime} S\right)$ isomer was not found in plasma samples taken after $28 \mathrm{~d}$ of salmon administration. The same holds true for differences between AST concentrations after intake of wild and aquacultured salmon, respectively (as stated above). One possible explanation may be that differences between food sources and configurational isomer distributions are observable only in low-dose and short-duration experiments. So by increasing the dose and/or the duration of the study a plateau will be reached as a result of saturation in absorption and/or isomerisation, and differences will no longer be observed.

Based on current knowledge, it is not possible to explain the differences in the bioavailability of AST from wild and aquacultured salmon, respectively, nor the differences in the isomer distribution in plasma compared with salmon. Therefore, further studies will be necessary to examine the bioavailability and distribution of AST optical isomers after intake of physiological doses.

\section{Acknowledgements}

The present study was supported by a grant of the Federal Ministry of Education and Research (BMBF-BEI032/ 0312248H/6). The authors thank U. Ostermeyer, Federal Research Centre for Nutrition and Food, Hamburg, Germany, for providing the yeast $X$. dendrorhous. We gratefully acknowledge the excellent technical assistance of S. Demirel, S. el Fahem, S. Herrmann and E. Hoch. 
A. B. and G. R. developed the initial idea, C. E. R. and K. B. collected and analysed the data. C. E. R. and A. B. performed the statistical analysis; C. E. R. drafted the manuscript. A. B. and J. M. designed the study, recruited and checked the volunteers, planned and scheduled meals, oversaw the kitchen personnel and handled, collected and stored all specimens. All co-authors participated in critically revising the manuscript. None of the authors had any conflict of interest.

\section{References}

1. Shaidi F, Metusalach A \& Brown JA (1998) Carotenoid pigments in seafoods and aquaculture. Crit Rev Food Sci Nutr 38, $1-67$

2. Nickell DC \& Springate JRC (2001) Pigmentation of farmed salmonoids. In Farmed Fish Quality, pp. 75-85 [S Kestin and C Warriss, editors]. Oxford, UK: Fishing New Books, Blackwell Publishing Ltd.

3. Putnam M (1991) A review of the nature, function, variability, and supply of pigments in salmonid fish. In Aquaculture and the Environment, no. 16, special publication, pp. 245-263 [N de Pauw and J Joyce, editors]. Gent, Belgium: European Aquaculture Society.

4. Guerin M, Huntley ME \& Olaizola M (2003) Haematococcus astaxanthin: applications for human health and nutrition. Trends Biotechnol 21, 210-216.

5. Bjerkeng B (1997) Chromatographic analysis of synthesized astaxanthin - a handy tool for the ecologist and the forensic chemist? Prog Fish Cult 59, 129-140.

6. Schiedt K, Leuenberger FJ \& Vecchi M (1981) Natural occurrence of enantiomeric and meso-astaxanthin. 5. Ex wild salmon (Salmo salar and Oncorhynchus). Helv Chim Acta 64, 449-457.

7. Turujman SA, Warner WG, Wie RR \& Albert RH (1997) Rapid liquid chromatographic method to distinguish wild salmon from aquacultured salmon fed synthetic astaxanthin. J AOAC Int $\mathbf{8 0}$, $622-632$

8. Ostermeyer U \& Schmidt T (2004) Differentiation of wild salmon, conventionally and organically farmed salmon. Dtsch Lebensm-Rundsch 100, 437-444.

9. Storebakken T, Foss P, Austreng E \& Liaaen-Jensen S (1985) Carotenoids in diets for salmonids: II. Epimerization studies with astaxanthin in Atlantic salmon. Aquaculture 44, 259-269.

10. Folch J, Lees M \& Sloane-Stanley GH (1957) A simple method for the isolation and purification of total lipides from animal tissues. J Biol Chem 226, 497-509.
11. Briviba K, Kulling SE, Moseneder J, Watzl B, Rechkemmer G \& Bub A (2004) Effects of supplementing a low-carotenoid diet with a tomato extract for 2 weeks on endogenous levels of DNA single strand breaks and immune functions in healthy nonsmokers and smokers. Carcinogenesis 25, 2373-2378.

12. Britton G (1995) UV/visible spectroscopy. In Carotenoids: Spectroscopy, pp. 57 [G Britton, S Liaaen-Jensen and H Pfander, editors]. Basel: Birkhaeuser Verlag.

13. van het Hof KH, West CE, Weststrate JA \& Hautvast JG (2000) Dietary factors that affect the bioavailability of carotenoids. J Nutr 130, 503-506.

14. Faulks RM \& Southon S (2005) Challenges to understanding and measuring carotenoid bioavailability. Biochim Biophys Acta 1740, 95-100.

15. Elmadfa I \& Majchrzak D (1999) Absorption und Transport von Astaxanthin und Canthaxanthin beim Menschen nach einer Lachsmahlzeit (Absorption and transport of astaxanthin and canthaxanthin in people after a salmon meal). Ernähr-Umsch 5, 173-177.

16. Mercke Odeberg J, Lignell A, Pettersson A \& Hoglund P (2003) Oral bioavailability of the antioxidant astaxanthin in humans is enhanced by incorporation of lipid based formulations. Eur J Pharm Sci 19, 299-304.

17. Osterlie M, Bjerkeng B \& Liaaen-Jensen S (2000) Plasma appearance and distribution of astaxanthin $\mathrm{E} / \mathrm{Z}$ and $\mathrm{R} / \mathrm{S}$ isomers in plasma lipoproteins of men after single dose administration of astaxanthin. J Nutr Biochem 11, 482-490.

18. Coral-Hinostroza GN, Ytrestoyl T, Ruyter B \& Bjerkeng B (2004) Plasma appearance of unesterified astaxanthin geometrical E/Z and optical R/S isomers in men given single doses of a mixture of optical 3 and $3^{\prime} \mathrm{R} / \mathrm{S}$ isomers of astaxanthin fatty acyl diesters. Comp Biochem Physiol C Toxicol Pharmacol 139, 99-110.

19. Kistler A, Liechti H, Pichard L, Wolz E, Oesterhelt G, Hayes A \& Maurel P (2002) Metabolism and CYP-inducer properties of astaxanthin in man and primary human hepatocytes. Arch Toxicol 75, 665-675.

20. Osterlie M, Bjerkeng B \& Liaaen-Jensen S (1999) Accumulation of astaxanthin all-E, $9 \mathrm{Z}$ and $13 \mathrm{Z}$ geometrical isomers and 3 and $3^{\prime}$ RS optical isomers in rainbow trout (Oncorhynchus mykiss) is selective. J Nutr 129, 391-398.

21. Foss P, Storebakken T, Austreng E \& Liaaen-Jensen S (1987) Carotenoids in diets for salmonids: V. Pigmentation of rainbow trout and sea trout with astaxanthin and astaxanthin dipalmitate in comparison with cantaxanthin. Aquaculture 65, 364-377. 